\title{
Environmental Management of Larg Supply Chain: A Diagnostic Instrument Proposed for Assessing Suppliers
}

\author{
Josiano Cesar de Sousa ${ }^{1, *}$ \\ ${ }^{1}$ Universidade do Vale do Rio dos Sinos, São Leopoldo, RS, Brasil \\ Murilo Barros Alves ${ }^{1, \dagger}$ \\ ${ }^{1}$ Universidade do Vale do Rio dos Sinos, São Leopoldo, RS, Brasil \\ Leonardo Leocádio ${ }^{2, \Omega}$ \\ ${ }^{2}$ Universidade Federal de Santa Catarina, Florianópolis, SC, Brasil \\ Jaqueline Rossato ${ }^{2, \%}$ \\ ${ }^{2}$ Universidade Federal de Santa Catarina, Florianópolis, SC, Brasil
}

\begin{abstract}
This article addresses Supply Chain Management (SCM), focusing specifically on environmental management systems. A systematic review of the literature identified gaps in SCM studies and supported the development of a diagnostic tool model capable of measuring the level of involvement of suppliers in a Supply Chain (CS) with the Environmental Management program of a focal firm. The results of this study were synthesized in a diagnostic tool on which elaboration was based on the LARG SCM model, the Dynamic Capabilities model, and the Learning to Grow Methodology. The proposed model was structured to measure, through a graph, the level of involvement of the suppliers of an SC with the environmental management requirements based on ISO 14001: 2015. The model was tested on the supply chain of a company that was included in the ISE (2017) Corporate Sustainability Index and was validated by the surveyed company.
\end{abstract}

\section{KEYWORDS}

Environmental Management, Supply Chain, Diagnostic Instrument.
CORRESPONDING AUTHOR

*Josiano Cesar de Sousa

Email: josianocesar@hotmail.com

${ }^{\dagger}$ Murilo Barros Alves

Email: muriloimp@gmail.com

$\Omega$ Leonardo Leocádio

Email: leoleocadio@gmail.com

¥ Jaqueline Rossato

Email: inerossato@gmail.com

Received: 08/01/2019.

Revised: 01/04/2019.

Accepted: 07/05/2019.

Published Online: 11/10/2019.

DOI: http://dx.doi.org/10.15728/bbr.2019.16.6.1 


\section{INTRODUCTION}

The challenges of managing a Supply Chain (SC) intensify as concerns about environmental impacts arise based on the exploration of its activity. Thus, the focal firm will try to develop a philosophy of work that aims to encourage the involvement of all suppliers with its own sustainability objectives (Srivastava, 2007). According to Seuring \& Muller (2008), a focal firm establishes the rules or governs the SC. In this context, the evolution of concerns about environmental responsibility has arisen a new concept in the literature: Green Supply Chain Management - GrSCM (Srivastava, 2007), strengthening environmental responsibility and requiring the development of controlling tools such as the Environmental Management Systems (EMS).

From this reality, as associated with the necessity of an increasingly efficient SC, emerges the LARG concept for SCM (Azevedo, Carvalho, \& Cruz-Machado, 2011), based on four paradigms, which are: Lean, Agile, Resilient, and Green. The aim of this new concept is to ally the focal firm's concerns about the financial and environmental sustainability to all the links in the SC. Therefore, there is a need to measure the capacity of the SC's suppliers to develop their activities in a sustainable way, helping the focal firm administer its environmental management policy more efficiently. This reduces potential risks through the implementation of development programs for suppliers, when needed.

Among the approaches researched in the literature, we highlight the contributions of Zhang, Kuo, Lu, \& Huang (2001); Dowlatshahi (2000); Bey (2001); Srivastava (2007); Seuring \& Muller (2008); Elkington (2002); Porter \& Van der Linde (1995a, b); Azevedo et al. (2011); Baramichai, Zimmers, \& Marangos (2007); Prahalad \& Hamel (1994); Helfat et al. (2007); Teece, Pisano and Shuen (1997); Souza et al. (2014); Eisenhardt and Martin (2000); Zollo \& Winter (2002); Hardwig, Bergstermann, \& North (2009); Souza et al. (2014); North, Silva Neto and Calle (2013); Holanda \& Souza (2016); Kamada (2017); and ISO 14001: 2015, which reinforce the necessity of adopting specific care measures in the field of Environmental Management.

Gaps that exist the research are reinforced by Masoumik, Abdul-Rashid and Olugu (2015), who state that "[i]n previous studies little attention was given to providing the managers with a basis from which they could strategically prioritize these green initiatives across their companies' supply chains".

In view of the current scenario, the following question arises: Is it possible to develop a conceptual proposal model as an assessment instrument for SC contributing towards the green paradigm attendance by the focal firm? The literature presents a conceptual basis for developing a model that can be used as a diagnostic instrument. Thus, this article aims to develop a model that can help the focal firm in assessing the involvement level of its SC with environmental issues, as guided by ISO 14001: 2015 to improve the involvement of the supply chain network with the company's Environmental Management System. As a result, we developed a practical and objective model that can be adapted to different $S C$ realities and applied to companies in different sectors, producing equally efficient effects and accurate and reliable diagnosis, thus contributing to SCM.

The article is structured as follows: methodology in section 2; literature review in section 3, discussing the main concepts; results and discussions, section 4; and finally, the conclusion in section 5 . 


\section{METHODOLOGY}

This research uses the hypothetical-deductive method by means of a systematic literature review (Dresch, Lacerda, \& Júnior, 2015). This modeling is qualitative, which, according to Vergara (1999), can be classified as descriptive research, since it describes how a conceptual model can be applied to improve the supply chain management.

Regarding its means, according to Fink (1998), the proposed research is: a) bibliographical, since it is a systematized study on the investigated topics on material published in journals and scientific articles for a better understanding about the application of the LARG model and the Dynamic Capabilities in Supply Chains; and b) a documental investigation, by means of which we sought information about the history, the facts, and the events related to the supply chain management.

In this study, we conducted a systematic literature review in the Scopus database. We used PRISMA methodology - Preferred Reporting Items for Systematic Reviews and Meta-Analysis (Liberati et al., 2009) to identify how concepts on supply chain management have been addressed in literature and to search for possible gaps in previous studies.

For the database searches, we used the following keywords: "supply chain management" and "LARG" or "green supply chain" or "environmental management system". As a result, we found 4,043 documents. Then, we used temporal filter elements, which limited the search from 2014 to 2018, and open access and document type classification, resulting in 89 documents.

Afterwards, we read the titles and abstracts of all the articles we researched to identify those aligned with the studied subject. Inclusion and exclusion criteria were applied, resulting in 21 articles, which were downloaded and read in full, serving as a basis for this paper. Then, the snowball sample methodology was used to insert 32 new references, increasing the total number of articles to 53, which were read to elaborate on the present paper, as shown in Figure 1.

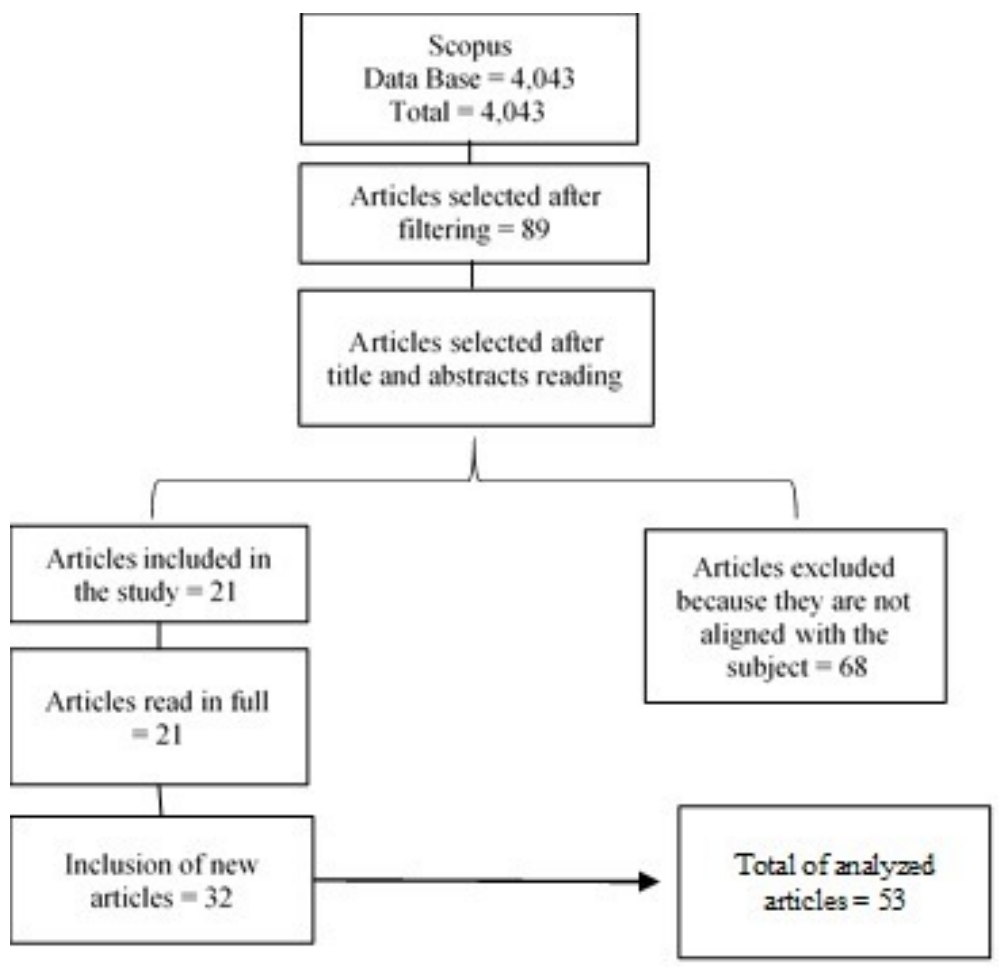

Figure 1. Systematic literature review phases: research, steps, and results.

Source: Elaborated by the authors (2018) 
The adopted methodological procedure allowed the elaboration of conceptual maps constructed using Vosviewer software (Velmurugan \& Radhakrishnan, 2015).

\section{LITERATURE REVIEW}

A supply chain (SC) is a service provider network that connects various entities, from customer to supplier, through manufacturing and services so that the flow of materials, money, and information can be effectively managed to meet the business requirements. Supply chain management (SCM) is one of the major challenges facing operational efficiency achievement, especially in times when environmental concerns are being increasingly valued, constituting true paradigms of sustainability (Azevedo, 2011).

Based on these precepts, a new concept emerges in the literature, seeking to include Supply Chain Management's concerns about the challenges of working in a supply chain that excels in environmental responsibility, thus leading to green supply chain management (GrSCM). GrSCM importance is promoted mainly by the increasing deterioration of the environment, for example, the decrease of raw materials resources, and the increased levels of waste flowing and pollution (Srivastava, 2007).

Among the initial approaches on concerns about GrSCM, there are the green design, addressed by Zhang et al. (1997); the Theory of Reverse Logistics, developed by Dowlatshahi (2000); and the industrial ecology and industrial ecosystems, as addressed by Bey (2001).

GrSCM has its roots in the environmental management and in the Supply Chain Management literature, adding the "green" component. It involves dealing with the influence and the relations between Supply Chain Management and the environment where it is inserted (Srivastava, 2007). One of its concerns is the sustainable development of the SCM.

Sustainable development is defined as "a development that meets the needs of the present without compromising the ability of future generations to meet their own needs" (WCED, 1987 as cited in Seuring \& Müller, 2008), advocating the idea that companies should operate based on the triple bottom line approach, according to which the minimum performance should be achieved in the environmental, economic and social dimensions (Elkington, 2002).

Srivastava (2007) defines GrSCM as "[i]ntegrating environmental thinking into a supply chain management, including product design, material resourcing and selection, manufacturing processes, delivery of the final product to the consumer as well as end-of-life management of the product after its useful life". In this way, GrSCM also involves Reverse Logistics processes.

When considering the complex considerations of green supply chain management, as presented by Srivastava (2007), it is possible to present a Supply Chain structure, according to Figure 2.

It is also important to emphasize that concerns about GrSCM should go beyond the operations management of the focal firm, since these operations can be responsible for the environmental and social performance of its suppliers. So, companies are invited to consider the environmental and social problems which exist throughout their supply chain (Seuring \& Müller, 2008).

Concern about sustainability in all the links of the supply chain originates an environmental responsibility concept, developing a philosophy of "green operations". Porter and Van der Linde $(1995 \mathrm{a}, \mathrm{b})$ indicate concerns with green fundamentals as a competitive initiative, emphasizing that it can be initiated from actions such as resource savings, waste elimination, and productivity improvement. 


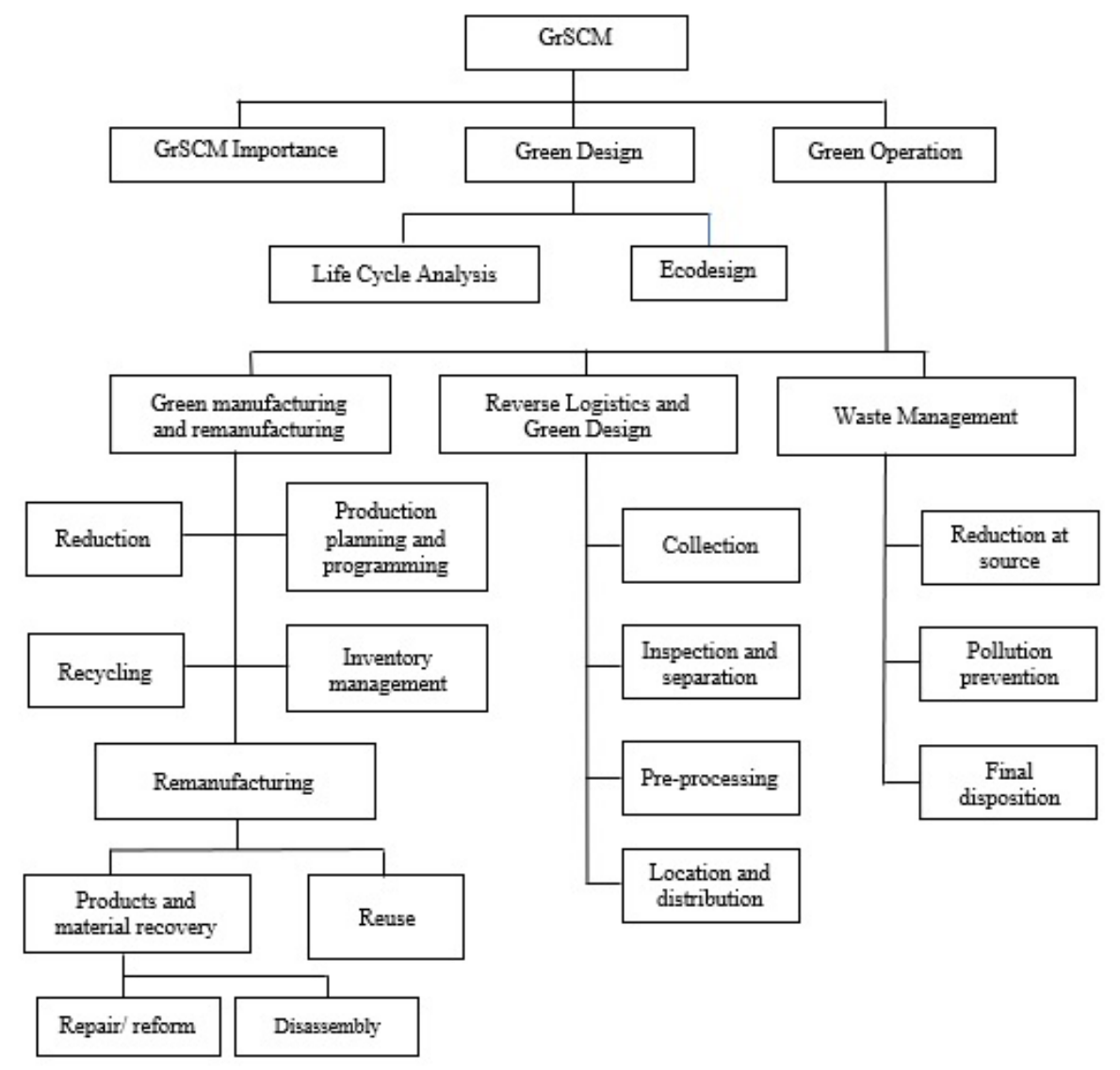

Figure 2. Complexity of green supply chain management

Source: Srivastava (2007)

\subsection{THE LARG MODEL}

These days, a SCM faces a great paradigm which is related to environmental responsibility. The existing literature indicates the application of a concept called LARG (Azevedo et al., 2011). The LARG model is based on four paradigms: Lean, Agile, Resilient, Green. These paradigms support the development of an SCM model which is structured in assumptions of concern about the financial and environmental sustainability of the Supply Chain.

The Lean paradigm was developed in Japan, as the basis of the Toyota Production System (TPS) (Ohno, 1998), and focuses on waste reduction, aiming to increase profitability by obtaining added value and consequently meeting customers' needs (Womack, Jones, \& Roos, 1991).

The Agile paradigm focuses on the establishment of capabilities that follow market changes in a quick and economical way (Agarwal, Shankar, \& Tiwari, 2007). So, the supply chain should promote integration among business partners to develop new competencies that meet the needs of the market (Baramichai et al., 2007).

The Resilient paradigm is structured by the ability of the company to adapt itself to the current market situation in order to avoid the possibility of undesirable changes compromising its performance. It aims to reduce the impact of these changes in the supply chain (Haimes, 2006).

The Green paradigm, for its turn, has its origin in the observed need of a company to pursue the achievement of its economic objectives by reducing environmental risks and impacts, improving its ecological efficiency as well as its business partners, and meeting environmental regulatory requirements (Hao \& Holt, 2005). 


\subsection{Dynamic Capabilities}

The need to explain how a company can perform better than others in the same market promoted a change in the focus of studies on the essential competencies, which started to prioritize internal analyses and indicated the company's internal abilities as the source of competitive advantage. Essential skills are "collective learning in the organization, especially how to coordinate diverse production skills and integrate multiple streams of technology" (Prahalad \& Hamel, 1994).

In order to survive and to be noteworthy in an environment of constant change, companies must develop their capacity to create, understand, and modify their ways of living, the so-called Dynamic Capabilities (Helfat et al., 2007). Dynamic Capabilities' theoretical foundations derive from the difficulty of understanding how a company presents superior performance when compared to others in an environment of constant change.

The literature on the subject does not reach a consensus on the term yet since the scholars in the area conceptualize this term emphasizing specific aspects of it. Thus, we present some definitions of Dynamic Capabilities below.

Teece et al. (1997) define dynamic capabilities as the "firm's ability to integrate, build, and reconfigure internal and external competencies to address rapidly changing environments". Thus, these capabilities reveal the ability of companies to achieve new and innovative forms of competitive advantage.

Souza et al. (2014) argue that "these capabilities, according to Teece (2007), are presented in three specific ways: (i) sensing, understood as the capacity to feel, perceive and configure opportunities and threats of the market; (ii) seizing, to take advantage of perceived capabilities; and (iii) managing and transforming, as the capacity to maintain competitiveness by means of continuous improvement, combining, protecting and reconfiguring the business organization".

Companies differentiate themselves in their competencies/capabilities, which represent a set of routines and organizational processes performed through their assets. These competencies correspond to the campanies' ways of organizing, doing things which cannot be done by market mechanisms. So, the internal properties of companies need to be understood in terms of organizational structures and managerial processes that support the productive activity of companies.

Dynamic Capabilities are unique processes that occur in companies. Eisenhardt and Martin (2000) indicate that the capabilities functionality can be duplicated in several companies. This happens because the Dynamic Capacities constitutive processes can be decoded and replicated, then, consequently, reproduced. Thus, the value of Dynamic Capabilities to obtain competitive advantage does not lie in the capabilities themselves, but in their capacity to create resources configurations.

Eisenhardt and Martin (2000) diverge from Teece et al. (1997) because the former argue that companies can develop their capabilities from several starting points and along different paths.

Zollo and Winter (2002) advocate for a position in which Dynamic Capabilities are derived from learning. They also argue that they constitute the company's systematic mechanisms to modify operational routines, stating that these mechanisms are: experience accumulation, knowledge articulation, and codification. For these authors, Dynamic Capabilities are "a learned and stable pattern of collective activity through which the organization systematically generates and modifies its operational routines in pursuit of improved effectiveness" (Zollo \& Winter, 2002, p. 340).

This definition presents the concept of Dynamic Capacities differentiating from operational capacity, which consists of a routine performance that can produce the company's results, goods 
or services. Dynamic Capabilities, on the other hand, are composed of a set of routines that can create organizational changes establishing a pattern that can be used repeatedly and reliably.

\subsection{Learning to Grow Methodology}

Based on the concepts of Dynamic Capabilities, Hardwig, Bergstermann and North (2009) developed the "Learning to Grow" methodology, which was successfully applied to 124 innovative and growing German Small and Micro Enterprises (SME) (Souza et al., 2014).

These authors argue that, according to the "Learning to Grow" methodology, the Wheel of Growth (North, Silva Neto, \& Calle, 2013) contributes to the development of essential growth competencies. The Wheel of Growth was developed based on enterprises' growth cycle concepts and contains issues elaborated and organized, focusing on four challenges that SME must pursue in their growth process: (1) sensing growth potentials; (2) designing growth opportunities; (3) seizing growth potentials; and (4) coping with growth and managing transformation (Souza et al., 2014), as shown in Figure 3.

Each one of these challenges has two groups, eight challenges in total. Souza et al. (2014) proposed a structure that also presents two questions for each one of the challenges, constituting, in this way, a total of 16 questions that will later originate 48 questions.

Going further frok this study, the Research and Development Group INOVAR of Universidade Federal do Maranhão, in partnership with the Sustainability Management Nucleus of Universidade Federal de Santa Catarina, have developed the Radar Growth Method (Netland \& Souza, 2016) based on the German "Learning to Grow" method (Hardwig, Bergstermann, \& North, 2009) - which objectifies to integrate, built and reconfigure internal and external competencies of

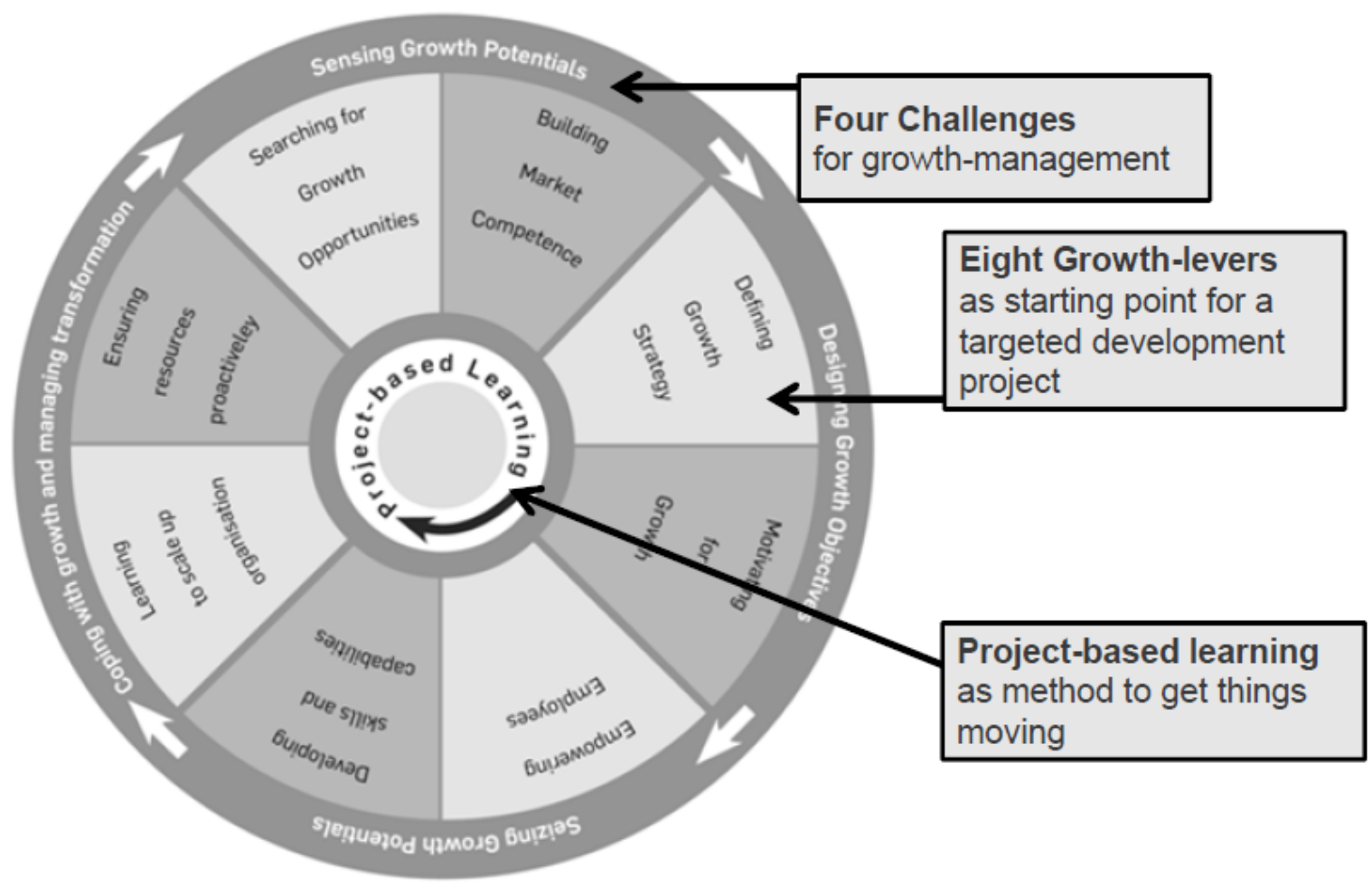

Figure 3. Wheel of Growth

Source: Hardwig; Bergstermann; North (2011) as cited in Souza et al. (2014) 
organizations - and on the Dynamic Capabilities concepts and knowledge management practices (Souza et al., 2013; Souza et al., 2014; Holanda \& Souza, 2016 as cited in Kamada, 2017).

Based on these precepts, we used contributions from the Radar Growth methodology to build the proposed model. This methodology suggests companies must continually: i) recognize opportunities; ii) plan growth; iii) implement opportunities; and (iv) manage growth, in order to grow and innovate in highly competitive markets (Kamada, 2017), as shown in Figure 4.

According to Kamada (2017), at first place, companies must recognize the existence of market opportunities that they do not use properly yet, considering each axis proposed by the Knowledge Radar Methodology. Thus, supplier companies that compose a supply chain should recognize opportunities for improvement and, to achieve this, it must monitor the environment to identify or create opportunities.

The Knowledge Radar methodology proposes, as a second step, the implementation of an action plan according to the identified opportunities. This can be accomplished by establishing objectives to follow market opportunities or involving employees in the creation process of strategies designed to reach the objectives of the company.

As a third step, companies must internally implement, in their processes, actions that could lead to, perceived opportunities. To make this possible, the company must encourage employees to think like entrepreneurs; and invest on training for employees to better perform their tasks.

Finally, as a fourth step, the Knowledge Radar methodology suggests managing growth to constantly ensure these skills in the routines of the company. The activities of organising growth or adapting the organization processes, along with providing resources, can allow this.

As a result of these assumptions, the internalization of these practices by companies allows the construction of a radar-based graph by which it is possible to diagnose how companies recognize opportunities, plan their growth, implement recognized opportunities and manage growth, thus indicating their strengths and weaknesses (Kamada, 2017). For this research elaboration purpose,

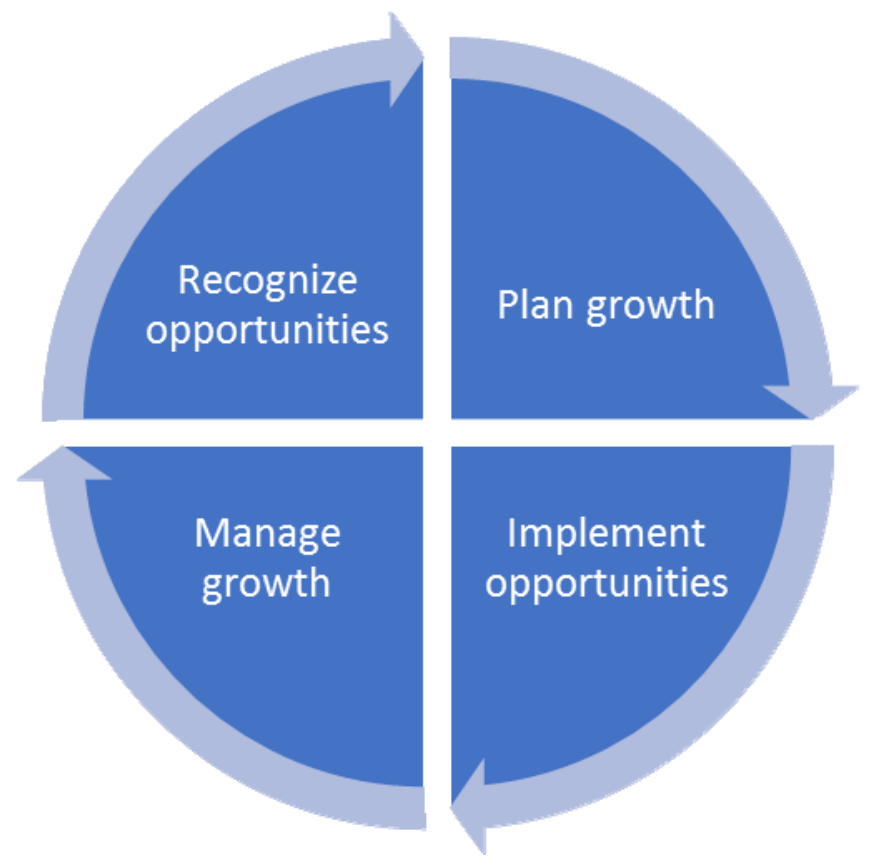

Figure 4. Wheel of Skills proposed by the Growth Radar Source: Kamada (2017) 
we have adapted aspects regarding supply chain management issues based on ISO 14001: 2015, as shown in Figure 5.

This research aims to establish a conceptual proposal that can be performed routinely using LARG model and Dynamic Capacities theory and the methodology proposed by Souza et al. (2014), based on the Learning to Grow Methodology. As a result, the company can learn through its own experiences, proposing a management structure that can be used to generate a competitive advantage throughout the supply chain.

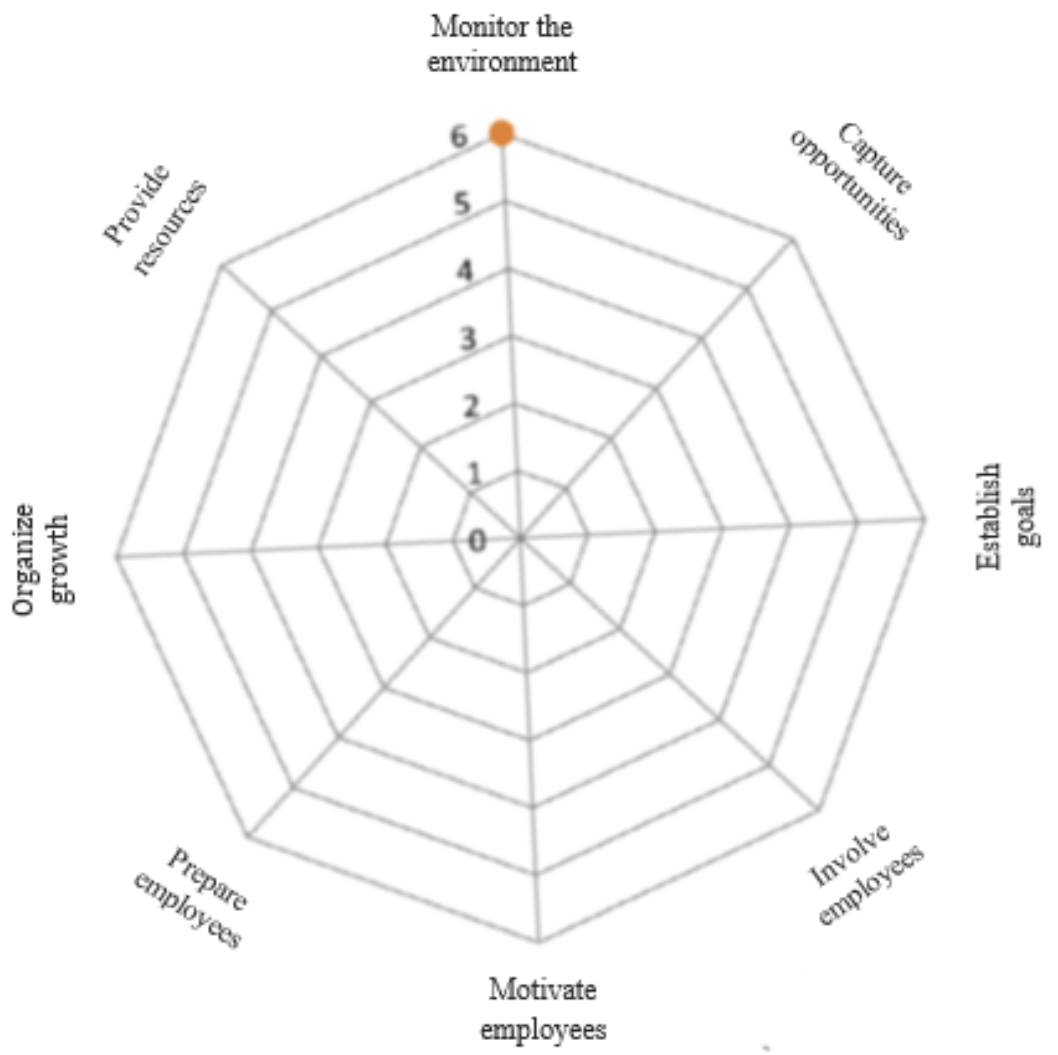

Figure 5. Growth Radar

Source: Holanda and Souza (2016) as cited in Kamada (2017)

\section{RESULTS AND DISCUSSION}

Once we have observed the particularities of GrSCM, the great challenge of elaborating a model proposal that can be used to perform a diagnosis that helps to improve the LARG supply chain management, which lies in the need to interpret and join several theories to elaborate a proposal capable of attending the peculiarities observed in this type of supply chain.

Through a systematic review of the literature, we could identify the countries which publish most on the subject: The United Kingdom and the United States, with 17 articles each; China, with 8 articles; along with Germany and Italy, who have 7 publications each. Figure 6 shows the most cited authors.

Another relevant factor is compliance with international standardization requirements. Therefore, we observed ISO 14001: 2015 guidelines that deal specifically with the criteria for managing companies' environmental issues, so they can improve their environmental performance. 
As to the auditable requirements of ISO 14001: 2015 were analysed to identify the main points in which companies must promote or develop control and/or monitoring tools, to propose a diagnostic model on how companies, which are part of the supply chain, discuss these themes.

The purpose of this diagnostic model is to identify whether supplier companies are concerned with the development of an environmental management system, in order to promote the maintenance of the focal firm's environmental management philosophy, in a way that contributes ecologically correct management to the development of a LARG supply chain.

The analyses performed allowed the design of a diagnostic tool proposal to help the focal firm in assessing how its suppliers deal with environmental issues and can contribute to fulfilling the necessary requirements to organize a LARG supply chain.

Besides the Dynamic Capabilities Approach (Teece et al., 1997; Sousa, 2014), we used the Learning to Grow Methodology (Hardwig, Bergstermann, \& North, 2009) to diagnose the supply chain management innovation capability. These references also support the proposal diagnostic method.

The four challenges proposed by the Learning to Grow Methodology were adapted to the supply chain management context: (i) company context; (ii) organizational planning; (iii) awareness and communication; and (iv) performance assessment. These four challenges have generated eight development axes, which, in their turn, produced 48 questions, rewritten based on ISO 14001: 2015. This aims to adapt these questions to the green supply chain management daily routine through a readjustment of the language used in this context. This adaptation is presented in Chart 1:

Two axes were defined to assess the "Company Context": "Monitor the Environment" and "Capture Opportunities". For each one, we elaborated two questions with three additional evaluations in each one. After this, we obtained the first inquiring module composed of 12 questions.

The second set of questions evaluates he way the supply chain addresses the issues related to Organizational Planning, as shown in Chart 2.

Likewise, it is important to emphasise the existence of two axes designed to answer questions about the way supply chain suppliers address issues regarding Organizational Planning. These are: "Establish Goals" and "Involve Employees". For each of these axes, two questions were

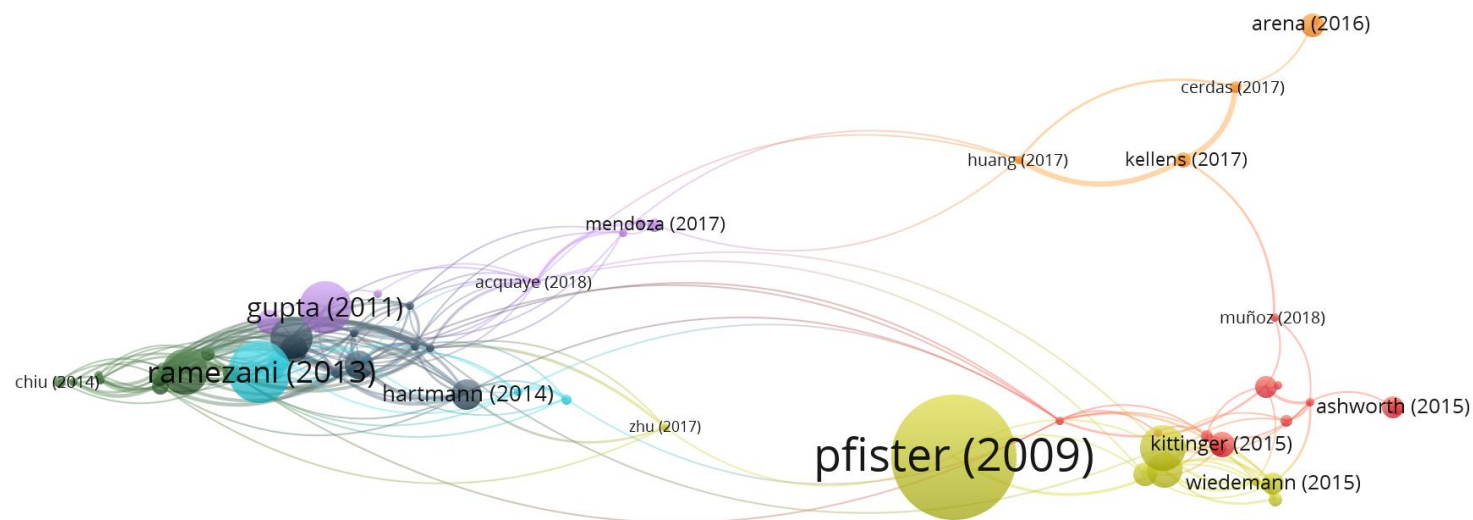

\& Vosviewer

Figure 6. Most cited authors

Source: Elaborated by the authors, 2018 
1. The company can determine internal and external issues that affect its capability to achieve the intended results. A) It knows the factors that can influence SME; B) knows the particularities of the local market where it is inserted; C) is constantly updated on environmental legislation.

Monitor the

environment 2. It understands the needs and expectations of the stakeholders and considers these expectations achievement as a goal. A) It knows who the stakeholders are; B) it knows the needs and expectations of the stakeholders; C) it knows which of these needs and expectations become legal requirements for other requirements.

Company Context

3. Keeps all documentation and certificates updated and available to interested parties. A) It holds all the certificates and municipal licenses; B) it holds all State certificates and licenses; C) it holds all Federal certificates and licenses.

Capture 4. It has a structured Environmental Management system and monitors the opportunities nature, scale, and environmental impacts of its activity. A) It has a continuous improvement system of environmental management; B) It has a system of continuous improvement of the processes that it develops; C) It maintains, in an operative way, an environmental management system.

Source: Elaborated by the authors.

\section{Chart 2}

Organizational Planning Issues

5. The company complies with legal requirements related to environmental management and ensures that the Environmental Management System can achieve the expected results. A) It establishes goals and objectives for environmental issues; B) It performs periodic assessment of the environmental management requirements; C) It defines objectives for environmental Establish management improvement.

goals

6. Determines the environmental aspects of the company's activities aiming to control or influence their environmental impacts. A) It determines the environmental aspects the company must consider; B) It has a contingency plan for emergencies or abnormal situations; C) It knows all its processes

Organizational which cause or may cause environmental impacts.

Planning

7. Motivates employees to achieve the outlined goals. A) Top management demonstrates leadership and commitment to the environmental management system; B) they ensure the provision of resources required for the environmental management system; C) They encourage people to contribute to the effectiveness of the environmental management system.

Involve employees

8. Ensures that employees are competent, due to training, to guarantee environmental performance and compliance with legal requirements. A) It has a qualification program for environmental management; B) It has an annual training schedule; C) It participates in meetings and congresses on environmental management. 

module composed of 12 other questions.

The third set of question aims to assess the way suppliers in the supply chain deal with issues regarding "Awareness and Communication", which was also divided into two axes: "Raise Awareness" and "Communicate and Document", according to Chart 3.

Following the same methodology, we elaborated two questions for these axes with three additional evaluations. Thus, we elaborated a third module composed of 12 questions.

Finally, a fourth and last module was structured to assess how suppliers deal with issues regarding "Performance Assesment". Again, the issues were structured in two main axes: "Monitor and Assess" and "Provide Resources". In the same way, 12 questions were generated, producing a total of 48 questions. The answers to these questions will produce a situational diagnosis regarding the propensity of providers to meet the necessary requirements to integrate a GrSCM, as shown in Chart 4.

Once we have formatted the four axes, it is possible to propose a diagnostic model capable of assessing the suppliers' ability to meet the requirements of a LARG supply chain, to help the focal firm in knowing each supplier's level of involvement in the development and management of its Environmental Management System.

Chart 3

Awareness and Communication Issues

9. Ensures that people are aware of the environmental management policy and its contribution to the effectiveness of the Environmental Management System. A) All employees know the environmental management policy; B) employees know the significant environmental aspects and the actual or potential environmental impacts associated with their work; C) employees are aware of their contribution to the Raise effectiveness of the Environmental Management System, including the Awareness benefits of improved environmental performance.

10. Clarifies the implications of not complying with the Environmental Management System. A) Employees know the implications of not complying with the requirements of the environmental management system, including non-compliance with requirements; B) employees are aware of the benefits of a good environmental performance for the company; C) employees are encouraged to propose ideas for improving

Awareness and the environmental management.

Communication

Communicate and Document
11. Establishes, implements, and maintains processes for internal and external communication, including what, when, by which means and how to communicate. A) In establishing its communication process, the company considers its legal requirements; B) the company ensures the consistency and reliability of the environmental information communicated according to information generated by the environmental management system; C) the company keeps documented information as evidence of an appropriate communication process.

12. It has the necessary documented information for the effectiveness of the Environmental Management System. A) It keeps a copy of all the institutional documentation made with the collaborators; B) the company communicates relevant information to the environmental management system among the various levels and functions of the organization; C) it ensures that its communication enables work to be controlled and contributes to its continuous improvement. 
1313. It provides an adequate number of properly calibrated equipment and

\section{resources required for the monitoring and assessment process of the EMS. A) It} provides the necessary resources for the monitoring and assessment of EMS; B)

Provide

Resources it determines an evaluation frequency to assure compliance with legal and other requirements; C) it provides resources intended to improve the EMS.

14. There is frequent internal auditing with established methods, responsibilities, and requirements. A) There is an internal audit team; B) there are established methods, responsibilities, and requirements; C) internal auditing is performed periodically.

Performance Assessment

Monitor and

15. It monitors, measures, and assesses its environmental performance. It also identifies what needs to be monitored and methods to monitor, measure, analyse, and assess. A) It conducts external audit; B) conducts regular periodic assessment; C) has defined applicable methods for monitoring, measuring, analysing, and assessing that ensure valid results.

Assess

16. The company has an established schedule for monitoring, measuring, and assessing the performance of its Environmental Management System. A) There is a periodic follow-up schedule; B) there are established performance indicators; C) it adopts corrective measures, when necessary.

Source: Elaborated by the authors

The proposed model will be structured by module, generating four large groups. These, in their turn, originate eight thematic axes, which allowe us to elaborate 48 questions, which, once answered by suppliers, will generate a radar chart image that will represent the supplier's ability to contribute to the Environmental Management System of the focal firm. The closer the diagram is to the outer edges, the more the supplier will be able to contribute positively. The closer it is to the centre, the harder to the supplier to meet the requirements. The proposed model is presented in Figure 7.

Once the proposed model has been applied, the focal firm can assess the inclination of its supply chain to contribute to achieving its EMS objectives, and thus propose the development of a set of measures to improve the performance of suppliers, when necessary.

Another great advantage of the model is allowing the elaboration of questions that can replace the existing ones and create a radar that meets the needs of each supply chain in a flexible way, without spoiling the analysis result.

After its elaboration, the proposed model was applied in a company included in the Corporate Sustainability Index - CSI 2017, of the Brazilian Bolsa de Mercadorias e Futuros (Mercantile and Futures Exchange - www.isebvmf.com.br). This company applied the model to a sample of 11 suppliers of its SC, producing information about its involvement with the environmental management criteria of the focal firm.

In the implementation phase of the model, we faced some difficulties, mainly regarding the suppliers' perception of their relevance in the environmental responsibility context in the focal firm. Some of the surveyed supplier companies stated that their activities did not cause any type of environmental impact, which confirms the lack of perception of the supply chain among suppliers. 


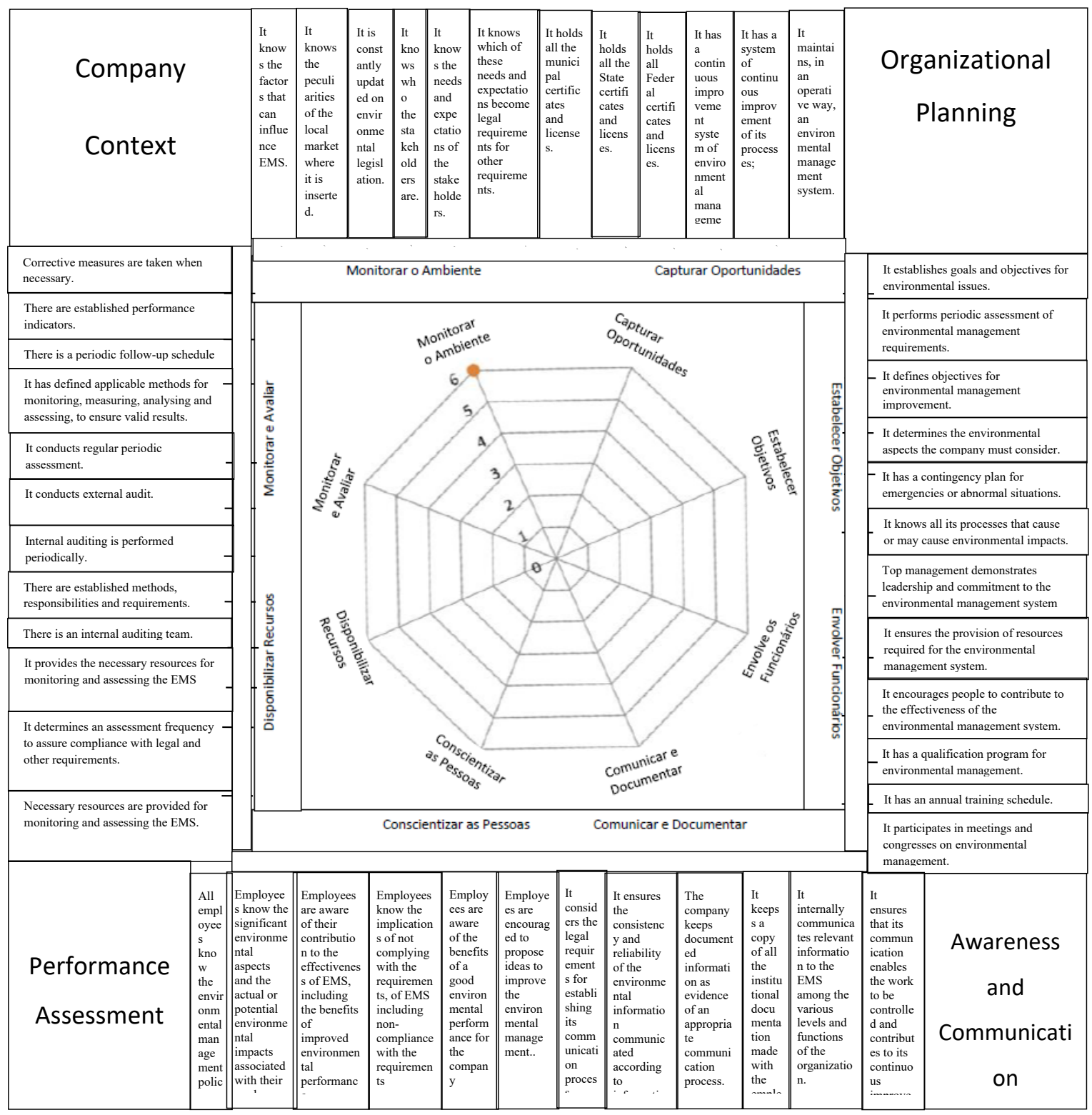

Figure 7. Proposed Model

Source: Adapted from Holland and Souza (2016)

At the end of the mapping, we could draw a graph representing the current situation of the assessed sample of suppliers (Figure 8), identifying how they are developing actions that can contribute to the achievement of the objectives and goals of the focal firm's EMS. The focal firm assessed the results of the work and considered the tool as adequate, emphasizing that it has contributed to identifying the supplier's degree of commitment or involvement with their EMS, thus validating the proposed model. 


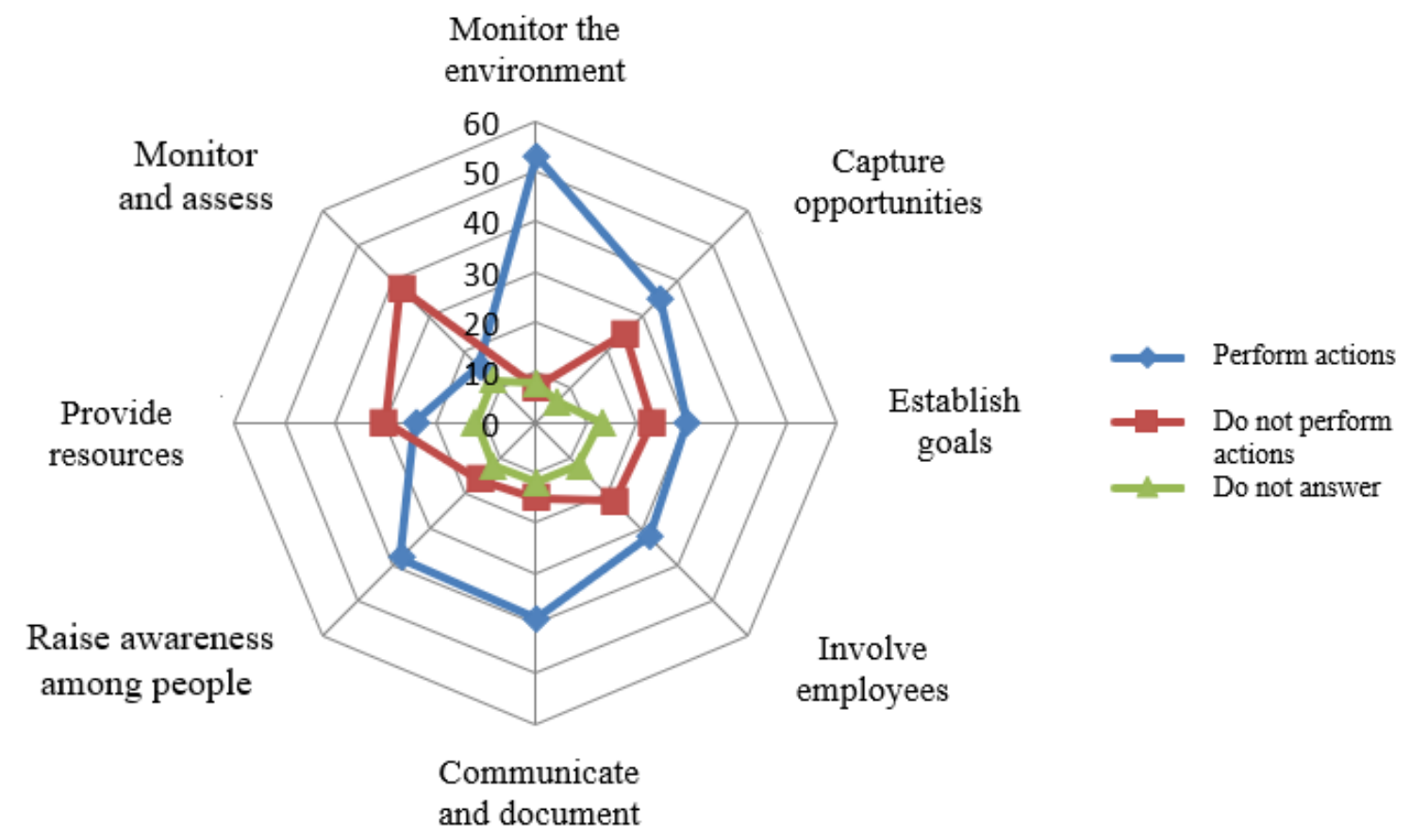

Figure 8. General representation of the involvement of Focal suppliers (Model validation) Source: Elaborated by the authors (2018)

\section{CONCLUSIONS}

This article aimed to present a diagnostic model capable of helping the focal firm to assess and measure whether its suppliers are adopting environmentally sustainable management practices in their companies management, in a way that contributes to a work philosophy that follows international standards such as those based on ISO 14001: 2014, contributing, this way, to the development of its EMS.

The conceptual base adopted has worked with a variety of academic accepted theories, such as those proposed by Srivastava (2007); Azevedo et al. (2011); Prahalad and Hamel (1994); Teece et al. (1997); Souza et al. (2014); Hardwig, Bergstermann and North (2009); North, Silva Neto and Calle (2013); Holanda and Souza (2016); and Kamada (2017). These references have contributed to ratify the relevance of the approached theme.

Despite the relevance and topicality of the subject, the systematic review of the literature revealed a shortage of publications approaching it from the point of view of the supplier management. We did not identify any model or proposal that could be used to assess the involvement level of suppliers with the Environmental Management System of the focal firm.

Our research made it possible to propose a model that, besides allowing a fast and safe diagnosis, presented in a graph the assessment result of suppliers' level of commitment with environmental issues. It also allows the focal firm inserting or replacing questions to adapt the proposed model in different levels of involvement of its SC suppliers. This way, it can assess their evolution regarding the management requirements of a GrSCM, based on the criteria and standards recommended by ISO 14001: 2015, to develop an EMS in accordance with international standards.

The proposed model was tested in a company listed on the Corporate Sustainability Index 2017 of the Brazilian Mercantile and Futures Exchange, which applied the model to a sample 
of 11 suppliers of its own supply chain. As a result, the focal firm was able to trace the suppliers' profile, noting their involvement level in achieving their EMS objectives. It also realized that some of these suppliers did not understand the impact of their performance on the Environmental Management System of the focal firm. By means of the research, with this sample of suppliers, the company discovered its supplier's level of involvement with its environmental management policy and validated the developed model.

As a limitation of this model use, we highlight how difficult it was to the network of suppliers to notice that their activities may impact the Environmental Management System of the focal firm. So, the development of a model that works to educate suppliers on their environmental responsibilities in the supply chain constitutes an issue for future researches.

Thus, we believe that the proposed model will positively contribute to the development of an assessment system capable of promoting an accurate and safe diagnosis that allows the improvement of environmental requirements of GrSCM, contributing to the LARG model philosophy development.

\section{REFERENCES}

Agarwal, R., Shankar, \& Tiwari, M. (2007). Modeling agility of supply chain. Industrial Marketing Management, 36(4), 443-457.

Azevedo, S. G, Carvalho, H., \& Cruz-Machado, V. (2011, April). A proposal of LARG supply chain management practices and a performance measurement system. International Journal of e-Education, e-Business, e-Management and e-Learning, 1(1), 7-14.

Baramichai, M., Zimmers, J., \& Marangos, A. (2007). Agile supply chain transformation matrix: An integrated tool for creating an agile enterprise. Supply Chain Management: An International Journal, 12(5), 334-348.

Bey, C. (2001). Quo vadis ecologia industrial? Greener Management International, 34, 35-42.

Denzin, N. K. (1978). The research act: A theoretical introduction to sociological methods (2nd ed.). New York: Mc Graw-Hill.

Dowlatshahi, S. (2000). Developing a theory of reverse logistics. Kansas City, Missouri: Interfaces.

Dresch, A., Lacerda, D. P., \& Júnior, J. A. V. A. (2015). Design science research: Research method for advancement of science and technology. Porto Alegre: Book.

Eisenhardt, K. M., \& Martin, J. A. (2000). Dynamic capabilities: What are they? Strategic Management Journal, Chichester, 21(10-11), 1105-1121.

Elkington, J. (2002). Cannibals partnerships from cannibals with forks: The triple iottom line of 21st-Century business. Oxford: Capstone.

Fink, A. (1998). Conducting research literature reviews: From paper to the internet. Thousand Oaks: Sábio.

Haimes, Y. Y. (2006). On the definition of vulnerabilities in measuring risks to infrastructures. Risk Analysis, 26(2), 293-296.

Rao P, \& Holt, D. (2005) Do green supply chains lead to competitiveness and economic performance? International Journal of Operations \& Production Management, 25(9), 898-916.

Hardwig, T., Bergstermann, M., \& North, K. (2009). Learning to grow: Developing growth competence of small-and medium-sized enterprises. Springer: Florianópolis. 
Helfat, C. E., Finkelstein, S., Mitchell, W., Petera F. M., Singh, H., Teece, D., Winter, S., \& Maritan, C. (2007). Dynamic capabilities and organizational processes. Dynamic capabilities: Understanding strategic change in organizations (pp. 30-45). London: Blackwell.

Hines, P., Holweg, M., \& Rich, N. (2004). Learning to evolve: A review of contemporary lean thinking. International Journal of Operations \& Production Management, 24(10), 994-1011.

Holanda, R. R., \& Souza, L. L. C. (2016, November). Gestao do conhecimento e desenvolvimento de capacidades dinâmicas em pequenas e medias empresas. Premio Fapema Maria Aragão. São Luís.

Kamada, P. M. (2017). Capacidade de crescimento e competitividade das pequenas empresas de Imperatriz - Maranhão (Master's thesis, Centro Universitário Alves Faria).

Liberati, A., Altman, D. G., Tetzlaff, J., Mulrow, C., Gotzsche, P. C., Ionnidis, J. P. A., Clarke, M., Devereaux, P. J., Kleijnen, J., \& Moher, D. (2009). The PRISMA statement for reporting systematic reviews and meta-analyses of studies that evaluate health care interventions: Explanation and elaboration. Journal PMED, 6(7), e1000100. doi:10.1371/journal.pmed.1000100

Masoumik, S. M., Abdul-Rashid, S. H., \& Olugu, E. U. (2015). The development of a strategic prioritisation method for green supply chain initiatives. PLoS ONE, 10(11), e0143115. doi:10.1371/journal.pone.0143115

North, K.; Silva Neto, \&.; Calle, G. D. (2013) Vencendo os desafios do crescimento: o método "aprender a crescer" para pequenas e médias empresas brasileiras. Navus - Revista de Gestão e Tecnologia, 3(1), 6-19.

Ohno, T. (1998). The Toyota production system. Productivity Press: Portland.

Porter, M. E., \& van der Linde, C. (1995a). Green and competitive: Ending the stalemate. Harvard Business Review, 73(5), 119-134.

Porter, M. E., \& van der Linde, C. (1995b). Towards a new conception of the environmental competitiveness relation. Journal of Economic Perspectives, 9, 97-118.

Prahalad, C., \& Hamel, G. (1994). Strategy as a field of study: Why search for a new paradigm? Strategic Management Journal, 15(S2), 5-16.

Prahalad, C. K., \& Ramaswamy, V. (2004a). Co-creation experiences: The next practice in value creation. Journal of Interactive Marketing, 18(3), 5-14.

Prahalad, C. K., \& Ramaswamy, V. (2004b). The future of competition. Executive Book Summaries, 26(3), part 1, 1-8.

Rao, P., \& Holt, D. (2005). Do green supply chains lead to competitiveness and economic performance? International Journal of Operations \& Production Management, 25(9), 898-916.

Seuring, S., \& Müller, M. (2008). From a literature review to a conceptual framework for sustainable supply chain management. Journal of Cleaner Production, 16, 1699-1710.

Souza, L. L. C., Holanda, R. R., Costa, E. C., \& Rossato, J. (2014, July/November). Metodologia para diagnosticar e avaliar a capacidade de crescer e inovar das pequenas e médias empresas. International Journal of Knowledge Engineering and Management, Florianópolis, 3(6), 246-273.

Souza, L. L. C., Holanda, R. R., Sousa, S. P., \& Costa, E. C. (2013, July/Dezember). Estratégias de inovação e crescimento sustentadas por práticas da gestão do Conhecimento. Navus - Revista de Gestão e Tecnologia, Florianópolis, 3(2), 89-104.

Srivastava, S. (2007, March). Green-supply chain management: A state-of-the-art literature review. International Journal of Management Reviews, 9(1), 53-80. 
Teece, D. J. (2007). Explicating dynamic capabilities: The nature and microfoundations of (sustainable) enterprise performance. Strategic Management Journal, 28(13), 1319-1350.

Teece, D. J., Pisano, G., \& Shuen, A. (1997, August). Dynamic capabilities and strategic management. Strategic Management Journal, Chichester, 18(7), 509-533.

Velmurugan, C., \& Radhakrishnan, N. (2015). Electronic Publishing: A Powerful Tool for Academic Institutions in the Electronic Environment. International Journal of Library Science and Information Management, 1, 10-18.

Vergara, S. (1999). Gestão de pessoas. São Paulo: Atlas.

Womack, J., Jones, D., \& Roos, D. (1991). The machine that change the world. HarperCollins Publishers, New York.

World Commission on Environment and Development. (1987). Our common future. Oxford: Oxford University Press.

Zhang, H. C., Kuo, T. C., Lu, H., \& Huang, S. H. (1997). Environmentally conscious design and manufacturing: A state-of-the-art survey. Journal of Manufacturing Systems, Dearborn, 16(5), 352371.

Zollo, M., \& Winter, S. G. (2002). Deliberate learning and the evolution of dynamic capabilities. Organization Science, 13(3), 339-351. 